\title{
G.C. Holt
}

\section{Lab-on-a-chip: Why aren't we all hypochondriacs?}

ABSTRACT. In the field of nanotechnology there has been considerable research into nanometresize sensors and microfluidics. In medicine, this confluence of technologies has resulted in the "lab-on-a-chip" concept, whereby blood analysis and other body fluid analysis to detect diseases may be conducted at home or at the point-of-care without the need for specialized laboratory equipment. Although the literature is full of research papers in this area, very few devices have made it successfully to market, albeit with some available to specialists in the health services but practically none available to the general public. Why is this? And why have cheap devices powered by a personal computer or smart phone not become commonplace in the home? This must have been the vision for many a research proposal in justifying funding because of the predicted burgeoning home healthcare market. The following is a review of where we are and the problems involved in realizing the dream of home-based healthcare.

Nanotechnology Perceptions 11 (2015) 20-26 